NASA/TM-2005-213986

Fabrication and Probabilistic Fracture Strength Prediction of High-Aspect-Ratio Single Crystal Silicon Carbide Microspecimens With Stress Concentration

Noel N. Nemeth and Laura J. Evans

Glenn Research Center, Cleveland, Ohio

Osama M. Jadaan

University of Wisconsin-Platteville, Platteville, Wisconsin

William N. Sharpe, Jr.

John Hopkins University, Baltimore, Maryland

Glenn M. Beheim

Glenn Research Center, Cleveland, Ohio

Mark A. Trapp

Carnegie Mellon University, Pittsburgh, Pennsylvania 
Since its founding, NASA has been dedicated to the advancement of aeronautics and space science. The NASA Scientific and Technical Information (STI) Program Office plays a key part in helping NASA maintain this important role.

The NASA STI Program Office is operated by Langley Research Center, the Lead Center for NASA's scientific and technical information. The NASA STI Program Office provides access to the NASA STI Database, the largest collection of aeronautical and space science STI in the world. The Program Office is also NASA's institutional mechanism for disseminating the results of its research and development activities. These results are published by NASA in the NASA STI Report Series, which includes the following report types:

- $\quad$ TECHNICAL PUBLICATION. Reports of completed research or a major significant phase of research that present the results of NASA programs and include extensive data or theoretical analysis. Includes compilations of significant scientific and technical data and information deemed to be of continuing reference value. NASA's counterpart of peerreviewed formal professional papers but has less stringent limitations on manuscript length and extent of graphic presentations.

- TECHNICAL MEMORANDUM. Scientific and technical findings that are preliminary or of specialized interest, e.g., quick release reports, working papers, and bibliographies that contain minimal annotation. Does not contain extensive analysis.

- CONTRACTOR REPORT. Scientific and technical findings by NASA-sponsored contractors and grantees.
- CONFERENCE PUBLICATION. Collected papers from scientific and technical conferences, symposia, seminars, or other meetings sponsored or cosponsored by NASA.

- SPECIAL PUBLICATION. Scientific, technical, or historical information from NASA programs, projects, and missions, often concerned with subjects having substantial public interest.

- TECHNICAL TRANSLATION. Englishlanguage translations of foreign scientific and technical material pertinent to NASA's mission.

Specialized services that complement the STI Program Office's diverse offerings include creating custom thesauri, building customized databases, organizing and publishing research results ... even providing videos.

For more information about the NASA STI Program Office, see the following:

- Access the NASA STI Program Home Page at http://www.sti.nasa.gov

- E-mail your question via the Internet to help@sti.nasa.gov

- Fax your question to the NASA Access Help Desk at 301-621-0134

- Telephone the NASA Access Help Desk at 301-621-0390

- Write to:

NASA Access Help Desk

NASA Center for AeroSpace Information 7121 Standard Drive

Hanover, MD 21076 
NASA/TM-2005-213986

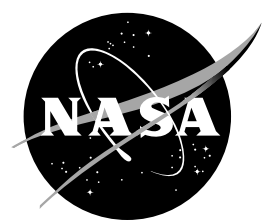

Fabrication and Probabilistic Fracture Strength Prediction of High-Aspect-Ratio Single Crystal Silicon Carbide Microspecimens With Stress Concentration

Noel N. Nemeth and Laura J. Evans

Glenn Research Center, Cleveland, Ohio

Osama M. Jadaan

University of Wisconsin-Platteville, Platteville, Wisconsin

William N. Sharpe, Jr.

John Hopkins University, Baltimore, Maryland

Glenn M. Beheim

Glenn Research Center, Cleveland, Ohio

Mark A. Trapp

Carnegie Mellon University, Pittsburgh, Pennsylvania

National Aeronautics and

Space Administration

Glenn Research Center 


\section{Acknowledgments}

We would like to acknowledge Stefan Reh, ANSYS, Inc., for his assistance with PDS and Eric Baker, Connecticut Reserve Technologies, for CARES/Life and programming assistance. The ANSYS/PDS - CARES/Life work was funded through NASA's Ultra Efficient Engines Technology program.

Trade names or manufacturers' names are used in this report for identification only. This usage does not constitute an official endorsement, either expressed or implied, by the National Aeronautics and Space Administration.

This work was sponsored by the Low Emissions Alternative

Power Project of the Vehicle Systems Program at the NASA Glenn Research Center.

Available from

NASA Center for Aerospace Information 7121 Standard Drive

Hanover, MD 21076
National Technical Information Service 5285 Port Royal Road Springfield, VA 22100 


\title{
Fabrication and Probabilistic Fracture Strength Prediction of High- Aspect-Ratio Single Crystal Silicon Carbide Microspecimens With Stress Concentration
}

\author{
Noel N. Nemeth and Laura J. Evans \\ National Aeronautics and Space Administration \\ Glenn Research Center \\ Cleveland, Ohio 44135 \\ Osama M. Jadaan \\ University of Wisconsin-Platteville \\ Platteville, Wisconsin 53818 \\ William N. Sharpe, Jr. \\ John Hopkins University \\ Department of Mechanical Engineering \\ Baltimore, Maryland 21218 \\ Glenn M. Beheim \\ National Aeronautics and Space Administration \\ Glenn Research Center \\ Cleveland, Ohio 44135 \\ Mark A. Trapp \\ Carnegie Mellon University \\ Department of Mechanical Engineering \\ Pittsburgh, Pennsylvania 15213
}

\begin{abstract}
Single crystal silicon carbide micro-sized tensile specimens were fabricated with deep reactive ion etching (DRIE) in order to investigate the effect of stress concentration on the room-temperature fracture strength. The fracture strength was defined as the level of stress at the highest stressed location in the structure at the instant of specimen rupture. Specimens with an elliptical hole, a circular hole, and without a hole (and hence with no stress concentration) were made. The average fracture strength of specimens with a higher stress concentration was larger than the average fracture strength of specimens with a lower stress concentration. Average strength of elliptical-hole, circular-hole, and without-hole specimens was $1.53,1.26$, and $0.66 \mathrm{GPa}$, respectively. Significant scatter in strength was observed with the Weibull modulus ranging between 2 and 6 . No fractographic examination was performed but it was assumed that the strength controlling flaws originated from etching grooves along the specimen side-walls. The increase of observed fracture strength with increasing stress concentration was compared to predictions made with the Weibull stress-integral formulation by using the NASA CARES/Life code. In the analysis isotropic material and fracture behavior was assumed - hence it was not a completely rigorous analysis. However, even with these assumptions good correlation was achieved for the circular-hole specimen data when using the specimen data without stress concentration as a baseline. Strength was over predicted for the elliptical-hole specimen data. Significant specimen-to-specimen dimensional variation existed in the elliptical-hole specimens due to variations in the nickel mask used in the etching. To simulate the additional effect of the dimensional variability on the probabilistic strength response for the single crystal specimens the ANSYS Probabilistic Design System (PDS) was used with CARES/Life.
\end{abstract}




\section{Introduction}

MicroElectroMechanical Systems (MEMS) that are being developed for power generation and propulsion (PowerMEMS) pose difficult design challenges with respect to strength and durability. For example miniature turbomachinery may rotate in excess of 1 million rpm and experience stresses of several hundred MPa while operating in a hot combustion environment (ref. 1). Silicon carbide (SiC) would be an excellent material choice for these harsh environment applications because of its ability to maintain strength, resist creep, and resist oxidation at gas turbine operating temperatures. At NASA's Glenn Research Center (GRC) work has been performed to develop SiC micro-fabrication technology as well as characterization and appropriate life prediction design methodology. This work was performed under NASA's Advanced Micromachining Technology for SiC Microengines project within the Alternate Energies Foundation Technologies (AEFT) program.

Our testing program had three purposes:

- First, to demonstrate fabrication of simple structures - microtensile specimens in this case - that have high aspect ratios (vertical dimension or etch depth divided by lateral feature size) with sufficient strength, surface finish, and dimensional tolerance suitable for PowerMEMS. A highly directional deep reactive ion etching (DRIE) process was used to fabricate the specimens (ref. 2).

- Second, to correlate process improvements with fracture strength response, where the fracture strength was defined as the level of stress at the highest stressed location in the structure at the instant of specimen rupture.

- And third, to test how well the Weibull probabilistic distribution works for miniature-sized SiC components. This was done with specimen geometries with various levels of stress concentration. This tested a fundamental premise of Weibull theory - that strength increases as the area (or volume) under highest stress decreases.

The increase in strength as the area (or volume) under highest stress decreases is known as the sizeeffect. Size effect has been investigated for miniature thin-film tensile specimens such as polysilicon (ref. 3) and a general review of the subject can be found in reference 4. Very little information exists in the literature for $\mathrm{SiC}$ at this size scale.

In this paper we describe work performed to predict the room-temperature strength of single crystal $\mathrm{SiC}$ micro-tensile specimens with introduced stress concentration using the Weibull distribution. This was done using GRC's Ceramics Analysis and Reliability Evaluation of Structures Life prediction program (CARES/Life) (refs. 5 and 6). We also demonstrate the feasibility of using CARES/Life with the ANSYS Probabilistic Design System (PDS) (ref. 7) to simulate or predict the strength response of brittle material components while simultaneously accounting for the effect of the variability of geometrical features on the strength response.

\section{Specimen Design and Fabrication}

The single crystal specimens were tested from one fabrication run during 2004 (which was designated as batch 6). The size scale of the specimens was appropriate for PowerMEMS turbomachinery. Because an improved micromachining process was used, the quality of these single crystal specimens was better than that of polycrystalline $\mathrm{SiC}$ specimens previously fabricated (ref. 8). The single crystal $\mathrm{SiC}$ was hexagonal $6 \mathrm{H}$ polytype with a $3.5^{\circ}$ off-axis orientation. Doping was n-type (resistivity $0.065 \mathrm{Ohm}-\mathrm{cm}$ ) and the material was research grade (ref. 9). The specimens were oriented parallel to the flat where the flat was the $\{10 \overline{1} 0\}$ plane. The wafer was lapped and polished from the backside to produce the final thickness of approximately $130 \mu \mathrm{m}$. The specimens were micromachined by DRIE using an inductively coupled plasma etcher (STS Multiplex ICP). 
The key to effective tensile testing is a specimen design that enables effective gripping. Screw or pinin-hole grip ends are obviously impractical at this size scale. Wedge-shaped specimen ends that fit into inserts in the grips is a design that was developed earlier for testing steel and nickel microspecimens (refs. 10 and 11). A traditional tensile specimen has a straight gage section, but there was concern that a straight specimen would break at the stress concentrations where it faired into the ends. This indeed turned out to be the case roughly half the time when tests were attempted on polycrystalline straight-gagesection specimens (ref. 8). We do not report on that data here. A specimen with a gentle curvature and smaller net cross-section avoids this problem while producing a uniform stress in the middle of the gage section. To generate a localized stress concentration a circular-hole and an elliptical-hole specimen were designed.

Figure 1 is a schematic of the basic geometries used for dogbone microtensile specimens. These specimens are actually rather large to be considered true MEMS, however, they are of appropriate size for PowerMEMS turbomachinery applications. The flared-end is the gripping section of the specimen and the gage section length is $1.3 \mathrm{~mm}$ with a designed cross section of 0.2 by $0.125 \mathrm{~mm}$. From left to right in the figure these are (a) curved, (b) circular-hole, and (c) elliptical-hole designs. These yielded stress concentrations relative to the net cross-section of (a) 1.01, (b) 2.3, and (c) 4.5, respectively based on results from finite element analysis. The curved specimen was $1 / 2$ the designed width or $0.1 \mathrm{~mm}$ at its narrowest point at the center. The central circular hole designed diameter was $1 / 2$ the width or $0.1 \mathrm{~mm}$ in diameter. The central ellipse was designed to be $0.1 \mathrm{~mm}$ across its major axis (perpendicular to the load axis) and $0.05 \mathrm{~mm}$ across its minor axis for a ratio of 2:1 between the major axis and the minor axis. The curved specimen geometry was the base-line from which we predicted the response of the other geometries.

The specimens were fabricated at GRC and tested at Johns Hopkins University (JHU). The etch mask was electroplated nickel, approximately $10 \mu \mathrm{m}$ thick. Wafers were etched using a time-multiplexed etchpassivate (TMEP) process, a technique widely used in the DRIE of silicon in order to form structures with aspect ratios greater than thirty (ref. 12). This technique alternates fluorine-plasma etching of the substrate with the deposition of a passivating polymer layer to produce an anisotropic profile (i.e., vertical sidewalls). In the DRIE of silicon using a fluorine plasma, the high reactivity of silicon with fluorine radicals causes fast lateral etching, which causes the etch mask to be undercut and reduces the aspect ratio attainable. On the other hand, $\mathrm{SiC}$ is relatively inert and appreciable etch rates using a fluorine plasma are obtained only when the $\mathrm{SiC}$ surface is subjected to ion bombardment. Since the ions are well collimated and strike only the horizontal surfaces of the substrate, the SiC etch process is inherently anisotropic. The lateral etch rate, however, while small, is not zero, which causes roughening of the side walls.

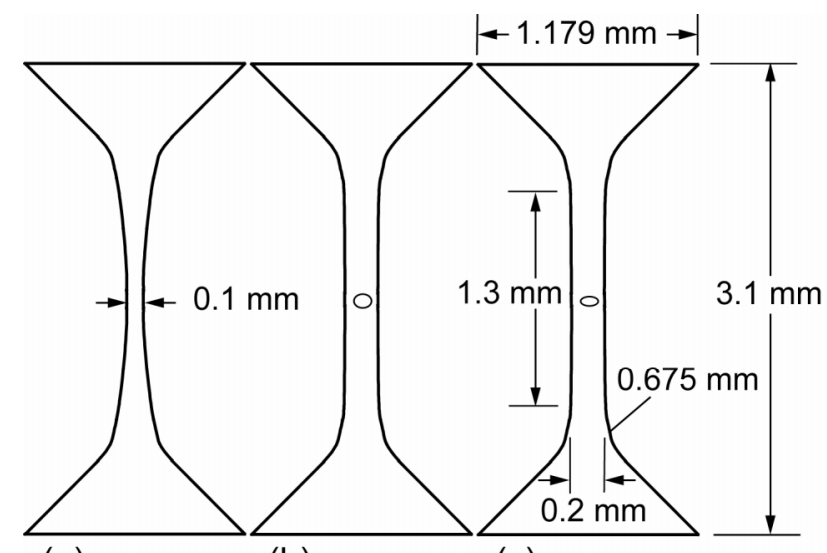

(a) (c)

Figure 1.-Basic schematic of the dogbone specimens (not to scale); (a) curved, (b) circular-hole, (c) ellipticalhole. The gage section is $1.3 \mathrm{~mm}$ in length. 
By utilizing a TMEP process, we have been able to fabricate $\mathrm{SiC}$ specimens with reduced side wall roughness and side walls with better verticality compared to specimens that were fabricated using an etchonly DRIE process (ref. 8). $\mathrm{SF}_{6}$ was used as the etching gas, while $\mathrm{C}_{4} \mathrm{~F}_{8}$ was used to deposit a fluorocarbon polymer film which protected the side walls from lateral etching. Pressure was held constant at approximately $12 \mathrm{mTorr}$, with $1000 \mathrm{~W}$ coil power and $75 \mathrm{~W}$ platen power applied during the etching step. The etch rate was approximately $0.2 \mu \mathrm{m} / \mathrm{min}$. Sides of the specimens were rougher than the unetched top and bottom surfaces, and exhibited vertical striations, as illustrated in figure 2. Any difference in side-wall roughness between the exterior surfaces and the interior surfaces of the holed features was not investigated.

The JHU team individually measured the dimensions of each specimen prior to fracture. The DRIE process used at GRC did not produce specimens with rectangular cross-sections; instead, because the sidewalls sloped outwards the specimens were wider at the base than at the top. A major goal of this project was to produce specimens with nearly vertical side walls and steady progress had been made as fabrication improved. Figure 3 shows an example of a cross-section for a specimen with a circular hole.

Tables 1 to 3 show the average specimen cross-sectional dimensions at the hole, or at the narrowest width (at the center) in the case of the curved specimen. The top surface is the nickel mask side and the bottom surface is opposite the nickel mask side. Note in table 3 that the elliptical-hole dimensions show significant scatter - particularly for the bottom minor axis. The dimensional variations were likely due to variations in the nickel mask used in the etching - resulting from uneven nickel plating and sloped sidewalls of the photoresist.
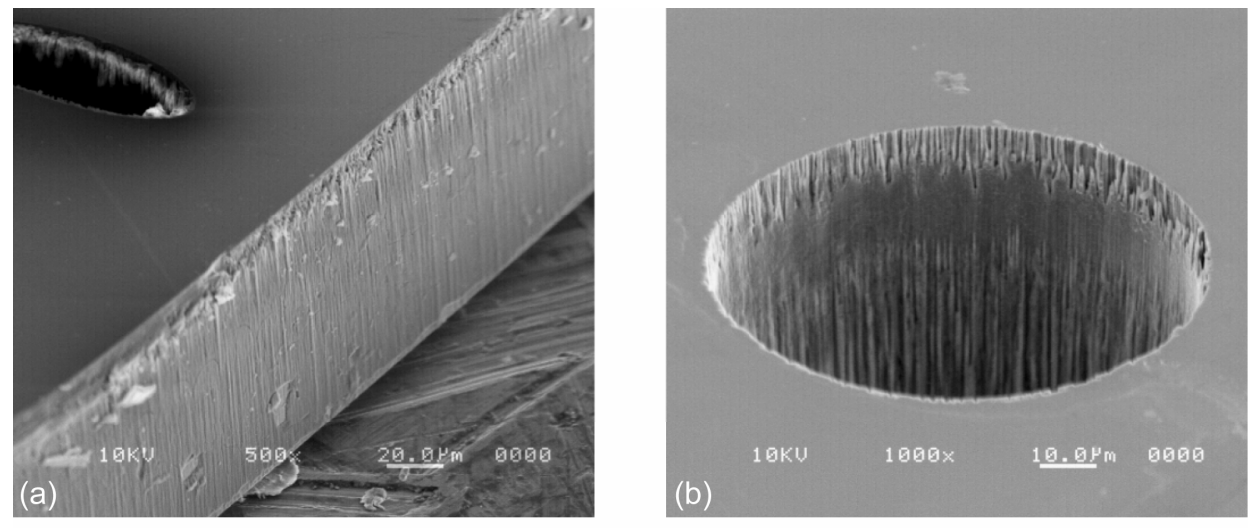

Figure 2.-SEM of etched side-walls; (a) close-up of an exterior side-wall of elliptical-hole specimen; (b) close-up of an interior side-wall of a circular-hole feature.

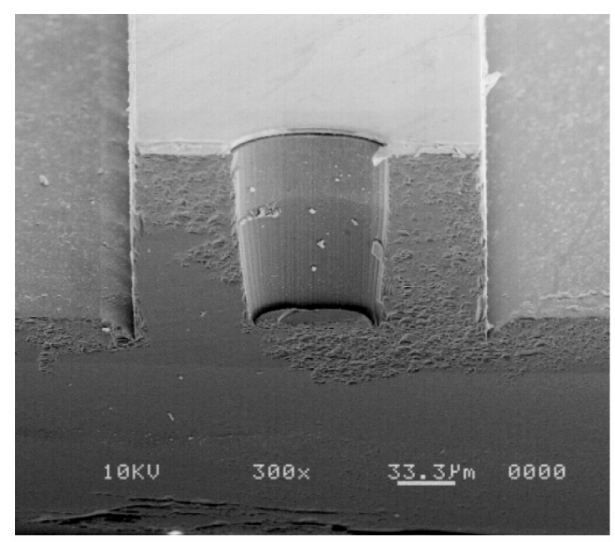

Figure 3.-Cross-section of a single crystal $\mathrm{SiC}$ test specimen with circular hole etched to a depth of $140 \mu \mathrm{m}$, as observed using SEM. Nickel mask is at the top. 
TABLE 1.-CURVED SPECIMEN AVERAGE CROSS-SECTIONAL DIMENSIONS (AT NARROWEST POINT); FOR $n=$ NUMBER OF SPECIMENS, $t=$ THICKNESS

(All dimensions in $\mu \mathrm{m}$ )

\begin{tabular}{|c|c|c|c|}
\hline$n$ & $t$ & Top Width & Bottom Width \\
\hline 19 & $127 \pm 2$ & $111 \pm 3$ & $125 \pm 7$ \\
\hline
\end{tabular}

TABLE 2.-CIRCULAR-HOLE SPECIMEN AVERAGE CROSS-SECTIONAL DIMENSIONS; FOR $n=$ NUMBER OF SPECIMENS, $t=$ THICKNESS

(All dimensions in $\mu \mathrm{m}$ )

\begin{tabular}{|c|c|c|c|c|c|}
\hline$n$ & $t$ & Top Width & Top Diameter & Bottom Width & Bottom Diameter \\
\hline 19 & $126 \pm 2$ & $210 \pm 3$ & $91 \pm 2$ & $223 \pm 7$ & $77 \pm 5$ \\
\hline
\end{tabular}

TABLE 3.-ELLIPTICAL-HOLE SPECIMEN AVERAGE CROSS-SECTIONAL DIMENSIONS; FOR $n=$ NUMBER OF SPECIMENS, $t=$ THICKNESS

\begin{tabular}{|c|c|c|c|c|c|c|c|}
\multicolumn{8}{c|}{ (All dimensions in $\mu \mathrm{m})$} \\
\hline$n$ & $t$ & $\begin{array}{c}\text { Top } \\
\text { Width }\end{array}$ & $\begin{array}{c}\text { Top Maj. } \\
\text { Axis }\end{array}$ & $\begin{array}{c}\text { Top Min. } \\
\text { Axis }\end{array}$ & $\begin{array}{c}\text { Bottom } \\
\text { Width }\end{array}$ & $\begin{array}{c}\text { Bottom Maj. } \\
\text { Axis }\end{array}$ & $\begin{array}{c}\text { Bottom Min. } \\
\text { Axis }\end{array}$ \\
\hline 18 & $127 \pm 1$ & $210 \pm 4$ & $91 \pm 4$ & $42 \pm 3$ & $225 \pm 7$ & $73 \pm 5$ & $26 \pm 8$ \\
\hline
\end{tabular}

\section{Experimental Procedure}

Figure 4 shows a microtensile specimen in a set of aluminum grips. Not shown in the figure are tapped holes for 0 to 80 screws, which fasten washers that cover the ends of the specimen. They do not grip the specimen, but capture the broken ends which would pop out on fracture. (A narrow strip of cellophane tape served the same purpose in later tests). One grip is fixed, and the other moves through a linear air bearing to reduce friction; it is attached with a thin steel wire to a load cell mounted on a motorized translation stage. A capacitance-based gage measured the displacement of an aluminum "flag" attached to the movable grip so that a force-displacement plot could be obtained. Displacement measurement was not necessary since only the strength was needed, but the plots were made to see if there was any unusual behavior (such as slipping as the specimen seats in the grips) during a test. The motorized stage was run at a constant rate for all tests - each taking a minute or so. Some details of the setup are given in reference 13.

Fractographic results (the examination of fractured surfaces from broken specimens) for the single crystal material were not available, however it was expected that sidewall grooves would be the source of the strength controlling flaws since those surfaces still showed significant roughness. Also, as demonstrated in references 14,15 , and 16 the strength response of small brittle structures is influenced by surface finish. It is therefore reasonable to assume that the strength response of sub-millimeter or micronsized structures is controlled by surface residing flaws that result from the micromachining process.

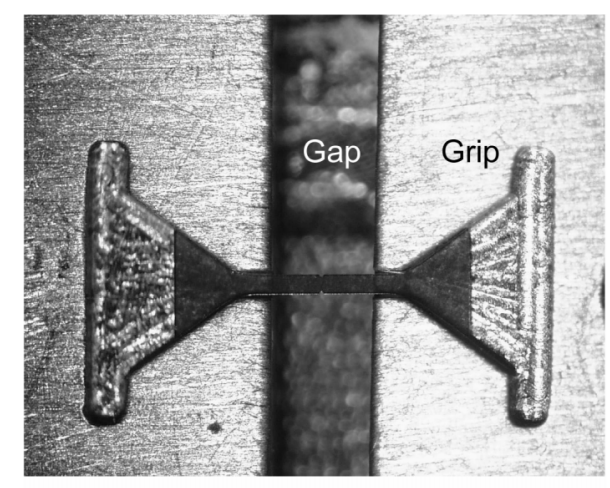

Figure 4.-A SiC specimen in aluminum grips. The specimen is $3.1 \mathrm{~mm}$ long. 


\section{Weibull Statistics and Cares/Life Analysis}

The CARES/Life software describes the probabilistic nature of brittle material strength using the Weibull cumulative distribution function. For uniaxially stressed components the 2-parameter Weibull distribution for surface residing flaws describes the component fast-fracture failure probability, $P_{f}$, as

$$
P_{f}=1-\exp \left[-\frac{1}{\sigma_{0}{ }^{m}} \int_{A} \sigma(x, y)^{m} d A\right]
$$

where $A$ is the surface area, $\sigma(x, y)$ is the uniaxial stress at a point location on that surface, and $m$ and $\sigma_{0}$ are the shape and scale parameters of the Weibull distribution, respectively. The shape parameter (or Weibull modulus) is a unitless measure of the dispersion of strength while the scale parameter is the characteristic strength (at $P_{f}=0.6321$ ) of a unit area of material in uniaxial tension and has units of

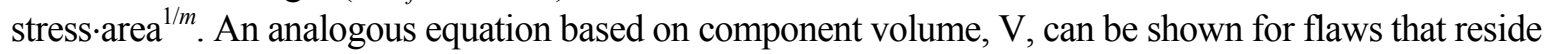
within the component.

Estimation of the Weibull parameters comes from rupture experiments of specimens (ideally 30 or more) in simple tension or flexure. Regression techniques such as least squares and maximum likelihood have been developed that can determine these parameters from a simplified form of equation (1);

$$
\begin{aligned}
P_{f} & =1-\exp \left[-\int_{A}\left(\frac{\sigma(x, y)}{\sigma_{f}}\right)^{m} d A\left(\frac{\sigma_{f}}{\sigma_{o}}\right)^{m}\right] \\
& =1-\exp \left[-A_{e}\left(\frac{\sigma_{f}}{\sigma_{o}}\right)^{m}\right]=1-\exp \left[-\left(\frac{\sigma_{f}}{\sigma_{\theta}}\right)^{m}\right]
\end{aligned}
$$

where $\sigma_{f}$ is the peak stress in the specimen, $\sigma_{\theta}$ is the specimen characteristic strength, and $A_{e}$ is known as the effective area. For component reliability that is a function of the volume, an analogous set of equations can be developed where $V_{e}$ is the effective volume.

The Weibull size effect is a direct consequence of equation (2) and predicts that the average strength of a large sized component is lower than that for a smaller sized component for identical loading and geometry. The magnitude of the size effect is a function of the effective area (or volume) and the Weibull modulus. For two different component geometry/loading combinations the size effect strength ratio is obtained by equating the probabilities of failure for the two different components resulting in

$$
\left(\frac{\sigma_{f, 2}}{\sigma_{f, 1}}\right)=\left(\frac{A_{e, 1}}{A_{e, 2}}\right)^{\frac{1}{m}}
$$

To predict the failure probability of specimen geometry 2 using the characteristic strength $\sigma_{\theta, 1}$ of the baseline specimen geometry 1 we used

$$
P_{f}=1-\exp \left[-\frac{A_{e, 2}}{A_{e, 1}}\left(\frac{\sigma_{f, 2}}{\sigma_{\theta, 1}}\right)^{m}\right]
$$

where in this case geometry 1 is for the curved specimen and geometry 2 is for the circular-hole or elliptical-hole specimen. 
In this work we study size-effect by using stress concentration. The central-hole specimen geometries were designed to have small effective areas relative to the curved specimen geometry so that a predicted size effect relative to the curved specimen would be large enough to easily stand out from the inherent scatter in the data. Confirmation of a size effect and the ability to predict it is a direct test of the applicability of the Weibull distribution to model the strength response of these materials at this size scale.

\section{Size Effect Study of The Single Crystal SiC With ANSYS/PDS}

In this section we demonstrate that CARES/Life can be used with the ANSYS Probabilistic Design System to account for the effect of stochastic variables - in this case the variability of specimen dimensions - on the specimen strength response. A rigorous analysis was not performed here because isotropic material and fracture behavior was assumed and therefore results should only be viewed as approximate.

The ANSYS Probabilistic Design System is an analysis tool which works with the ANSYS finiteelement analysis program. The ANSYS/PDS allows the effects of probabilistic loads, component geometry, and material properties to be considered in the analysis. It offers probabilistic analysis methods such as Monte Carlo simulation or Response Surface Method. Previously it has been shown that CARES/Life can be embedded within the ANSYS/PDS using ANSYS macros so that the effects of stochastic variables of component geometry, loading and material properties on the predicted strength and life can be assessed (ref. 17). For the analysis of the single crystal SiC (batch 6) specimens we have attempted to use CARES/Life with ANSYS/PDS to simulate the effect of dimensional variation on predicted failure probability. This was done because dimensional variation of the elliptical-hole specimen was significant (see table 3). Isotropic material and fracture behavior were assumed since CARES/Life does not have anisotropic reliability models for single crystals. All specimens had the same orientation parallel to the primary flat of the wafer and hence the same orientation relative to the crystallographic cleavage plane(s). The effect of multiaxial stresses on the cleavage plane(s) was not considered.

The strength responses of the circular-hole and elliptical-hole specimens were predicted using the curved specimen data as a baseline. These predictions were based on calculation of the effective side-wall area, $A_{e s w}$, of the specimen (see fig. 2) and not on the total effective area, $A_{e}$, of the specimen. The total effective area, $A_{e}$, of the specimen includes the top (nickel mask) surface, also the bottom (opposite the nickel-mask) surface, as well as the side-wall surfaces. The effective side-wall area, $A_{\text {esw }}$, only includes the etched side-wall area of the specimen and no other surfaces. The top and bottom surfaces were considerably less rough than the etched side-wall surfaces and were assumed to not contain critical strength controlling flaws. Hence, only the surfaces associated with the etched side-walls were assumed to contribute to the strength response. It was also assumed that the side-wall flaws resulting from etching along the interior hole feature were the same as the flaws resulting from etching on the exterior side-walls of the specimen (see fig. 2). All subsequent results are shown using first principal stress.

Table 4 shows the estimated Weibull parameters from the experimental data and their corresponding 90 percent confidence bounds. Note that the confidence bounds are a function of the sample size $n$ - the greater the number of specimens tested (for a given geometry) the narrower the bounds on the estimated parameters are. The peak stress $\sigma_{f}$ for each specimen was determined with ANSYS using the fracture loads and the individual measurements for each specimen cross section. Figure 5 shows the quarter-

TABLE 4.-BATCH 6 SINGLE CRYSTAL SIC STRENGTH AND MAXIMUM LIKELIHOOD ESTIMATED WEIBULL PARAMETERS; $n=$ NUMBER OF SPECIMENS, 90 PERCENT CONFIDENCE LIMITS

OF $m$ AND $\sigma \theta$ ARE IN PARENTHESIS

\begin{tabular}{|c|c|c|c|c|}
\hline Specimen & $n$ & $\begin{array}{c}\text { Avg. strength } \\
(\mathrm{GPa})\end{array}$ & $m$ & $\begin{array}{c}\sigma_{\theta} \\
(\mathrm{GPa})\end{array}$ \\
\hline Curved & 19 & $0.66 \pm 0.12$ & $5.9(4.1,7.5)$ & $0.71(0.66,0.77)$ \\
\hline Circular hole & 19 & $1.26 \pm 0.34$ & $3.8(2.6,4.8)$ & $1.38(1.23,1.55)$ \\
\hline Elliptical hole & 18 & $1.53 \pm 0.84$ & $2.0(1.4,2.6)$ & $1.74(1.39,2.18)$ \\
\hline
\end{tabular}




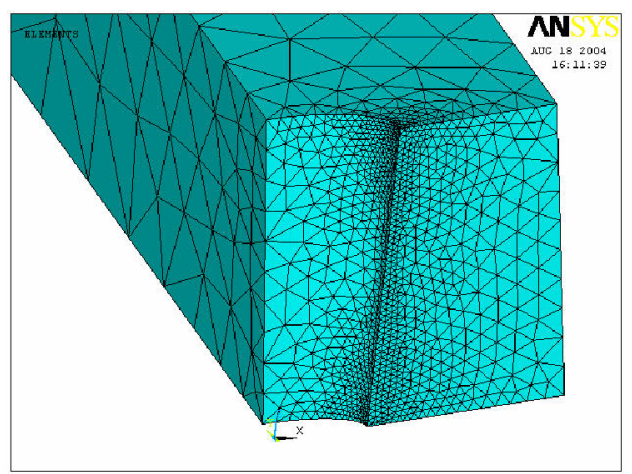

(a)

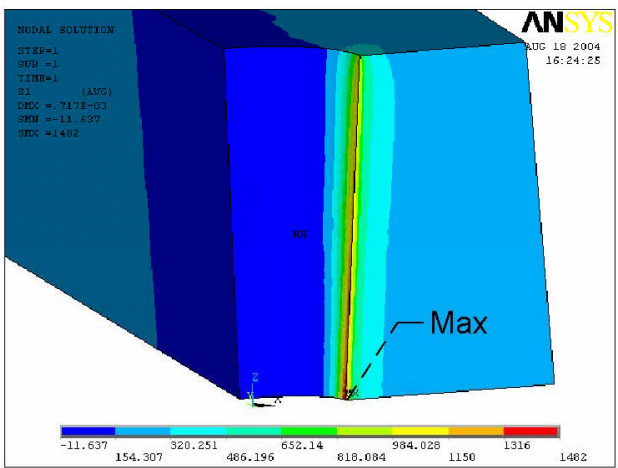

(c)

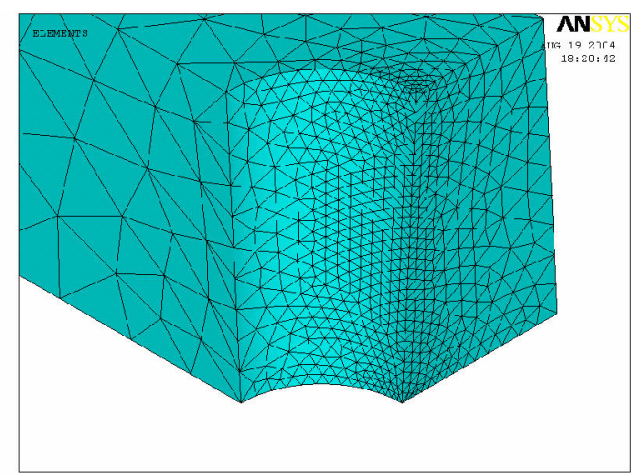

(b)

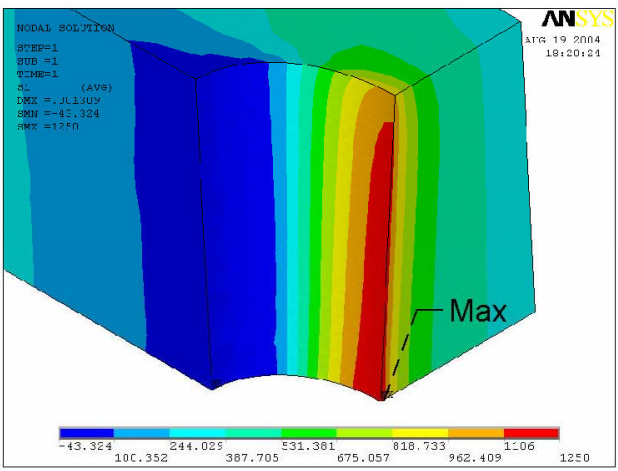

(d)

Figure 5.-Quarter-symmetry mesh and first principal stress solution for the elliptical-hole and circular-hole specimen using averaged specimen dimensions. Only the specimen gage section was modeled. The scale is in MPa.

symmetry mesh and first principal stress solution for the gage section of the elliptical-hole and circularhole specimens using average specimen dimensions. A uniform pressure was applied at the specimen end to simulate the load. The estimated Weibull modulus $m$ in table 4 appears to be lower for the circular-hole and elliptical-hole specimens. However, there was one particularly high value in the elliptical-hole data that had the dramatic effect of lowering the Weibull modulus from 3.9 (with the data point removed) down to 2.0 (with the data point included). The reason why the strength of this potential outlier point was significantly larger than the rest of the data was not determined and it was therefore not removed from the data set.

To simulate fracture strength data we took advantage of equation (4) and Monte-Carlo simulation. For the PDS simulations a normal distribution was used to describe the variation in the dimensions shown in tables 2 and 3. For the nickel mask side (the top side) the average dimensions and respective standard deviations were used. For the side opposite the nickel mask (the bottom side) the ratio of the taper from the nickel mask side to the opposite side multiplied by the nickel mask side dimension was used. For a given trial within a simulation a random number generator was used to choose a $P_{f}$, then using the ANSYS model generated from the trial, the effective area of the specimen side-walls, $A_{e s w}$, (see fig. 2) was calculated using the baseline Weibull modulus with CARES/Life and a predefined deterministic load. The load magnitude was arbitrarily assigned since the effective area was independent of the load magnitude for this case. Finally $\sigma_{f}$ for the trial was calculated from equation (4) using the baseline data and the randomly generated $P_{f}$ value. The result was a collection of $n$ fracture strengths that could be ordered from lowest to highest value; $\sigma_{f, 1}, \sigma_{f, 2}, \ldots \sigma_{f, i}, \ldots, \sigma_{f, n}$. These values were then ranked similar to experimental fracture data using the formula 


$$
P_{f, i}=\frac{i-0.5}{n}
$$

and plotted for ranked failure probability versus fracture strength.

Using the procedure outlined above, simulations for 200 specimens of the circular-hole and ellipticalhole specimen types were run. The curved-specimen was used as the baseline. These results are shown in table 5 and figures 6 and 7. The simulations were generated using a Weibull modulus $m$ of 6.5 , which was the value obtained from the fracture forces for the curved specimen and $\sigma_{\theta}$ of $0.71 \mathrm{GPa}$. Table 5 shows the maximum likelihood estimates of parameters from the simulations for the elliptical hole-specimen had a lower estimated Weibull modulus compared to the curved specimen baseline Weibull modulus. This was because the elliptical-hole specimen was affected to a greater degree by dimensional variability. This fact was confirmed when the effective side-wall area $A_{e s w}$ versus failure probability $P_{f}$ was compared for the elliptical-hole specimen. The $A_{\text {esw }}$ value tended to be larger at low $P_{f}$ and smaller at high $P_{f}$. This is shown in table 6 for the lower, middle, and upper third of the failure probability distribution for the circular- and elliptical-hole specimens. The implication is that when $A_{\text {esw }}$ is large fracture strength tends to be lower and when $A_{e s w}$ is small fracture strength tends to be larger. Therefore increased scatter in the fracture strengths, and hence a lower Weibull modulus, is observed when $A_{\text {esw }}$ varies within a set of specimens versus when $A_{e s w}$ is constant. Table 6 shows that the coefficient of variation (standard deviation divided by the mean) of $A_{e s w}$ is an order of magnitude smaller for the circular-hole specimens than the elliptical-hole specimens. This means that the effect of variability of dimensions on strength for the circular-hole specimens is much smaller than for the elliptical-hole specimens.

TABLE 5.-WEIBULL PARAMETERS ESTIMATED FROM THE PDS SIMULATIONS USING MAXIMUM LIKELIHOOD. 90 PERCENT CONFIDENCE LIMITS OF $m$ AND $\sigma_{\theta}$ ARE IN PARENTHESIS

\begin{tabular}{|l|c|c|c|c|}
\hline \multicolumn{1}{|c|}{ Specimen } & $\begin{array}{c}\text { No. simulated specimens, } \\
n\end{array}$ & $m$ & $\begin{array}{c}\sigma \theta \\
(\mathrm{GPa})\end{array}$ & $\begin{array}{c}\text { Avg. } A_{\text {esw }} \\
\left(\mathrm{mm}^{2}\right)\end{array}$ \\
\hline Curved & --- & 6.5 & 0.71 & 0.15 \\
\hline Circular-hole & 200 & $5.9(5.4,6.5)$ & $1.24(1.22,1.27)$ & 0.0039 \\
\hline Elliptical-hole & 200 & $4.1(3.7,4.5)$ & $1.87(1.83,1.94)$ & 0.00050 \\
\hline
\end{tabular}

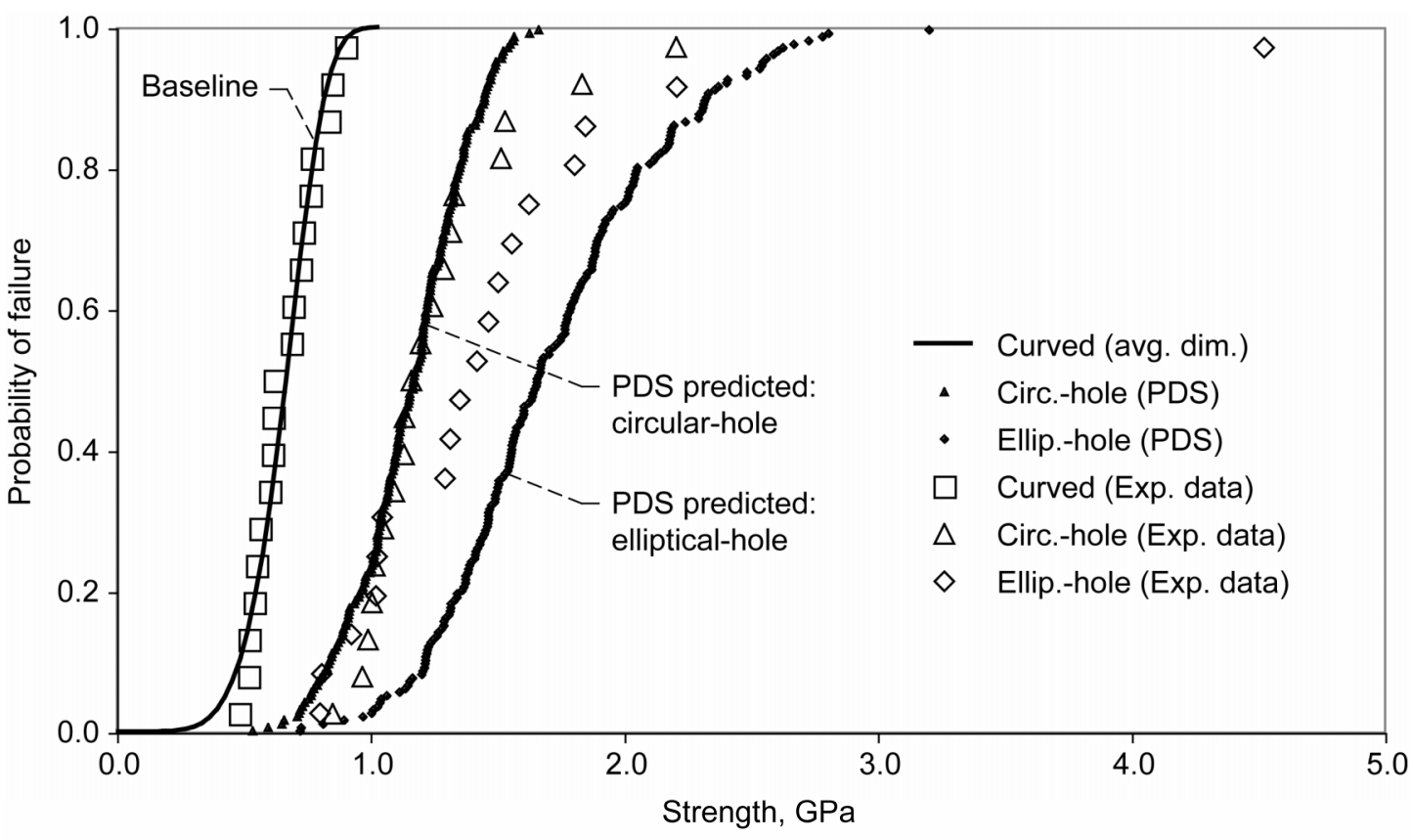

Figure 6.-Cumulative distribution plot of CARES/Life \& ANSYS/PDS Monte-Carlo simulation results of 200 predicted fracture stresses for the circular-hole and elliptical-hole specimen types compared to experimental data. The Weibull parameters estimated from the curved specimen data were used as a baseline to predict the strength response of the other specimen geometries. 


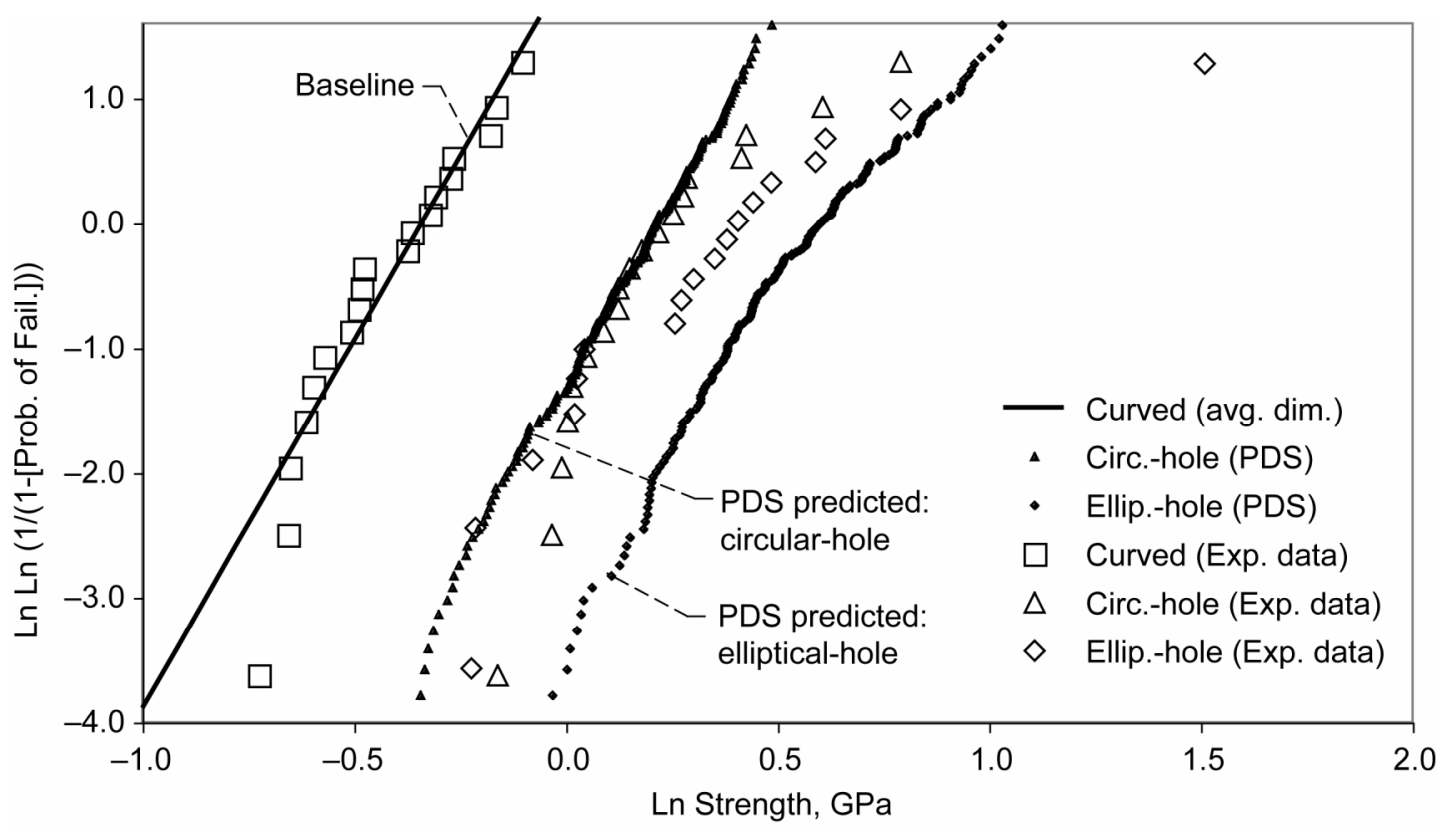

Figure 7.-Weibull plot form of CARES/Life \& ANSYS/PDS Monte-Carlo simulation of 200 predicted fracture stresses for the circular-hole and elliptical-hole specimen types compared to experimental data. The Weibull parameters estimated from the curved specimen data were used as a baseline to predict the strength response of the other specimen geometries.

TABLE 6.-AVERAGE AND STANDARD DEVIATION OF SIDE-WALL EFFECTIVE AREA, $A_{E S W}$, CALCULATED FROM EACH TRIAL OF THE PDS SIMULATIONS FOR THE LOWER THIRD, MIDDLE THIRD, AND UPPER THIRD OF THE PROBABILITY OF FAILURE DISTRIBUTION.

\begin{tabular}{|l|c|c|c|}
\hline \multicolumn{1}{|c|}{ Specimen } & $\begin{array}{c}A_{\text {esw }} \\
\left(0 \% \leq P_{f}<33 \%\right) \\
\left(\mathrm{mm}^{2}\right)\end{array}$ & $\begin{array}{c}A_{\text {esw }} \\
\left(33 \% \leq P_{f}<66 \%\right) \\
\left(\mathrm{mm}^{2}\right)\end{array}$ & $\begin{array}{c}A_{\text {esw }} \\
\left(66 \% \leq P_{f} \leq 100 \%\right) \\
\left(\mathrm{mm}^{2}\right)\end{array}$ \\
\hline Circular-hole & $0.0039 \pm 0.00037$ & $0.0040 \pm 0.00043$ & $0.0039 \pm 0.00038$ \\
\hline Elliptical-hole & $0.00078 \pm 0.00047$ & $0.00053 \pm 0.00042$ & $0.00020 \pm 0.00016$ \\
\hline
\end{tabular}

Figures 6 and 7 show the CARES/Life \& ANSYS/PDS simulation results compared to the experimental data. Figure 7 is a Weibull plot of the data in figure 6 . The experimental data did show an appreciable size effect - although less than was expected for the elliptical-hole data. The curved specimen data was used as the baseline and it can be seen that the Weibull parameters chosen fit the curved specimen experimental data very well — as it should have. Very good correlation was achieved for the circular-hole specimen. For the elliptical-hole specimen the simulation tended to over predict the strength. Nonetheless these results were encouraging. It is interesting to note the non-linear character of the simulation for the elliptical-hole specimens in figure 7. The authors speculate that the elliptical specimens may have deviated from a true elliptical shape and also that the area under highest stress was very localized and possibly affected by the surface roughness. This could have caused errors in the finite element analysis of the stresses and consequently effected the strength predictions. Another potential source of error involved the assumption that the surface roughness (and hence strength response) was the same for the curved specimens exterior side-walls as for the elliptical specimens interior side-walls at the hole. Finally, from table 4 it should be pointed out that only 18 elliptical-hole specimens were tested and that the magnitude of the confidence bounds on characteristic strength $\sigma_{\theta}$ was significant. This indicates that some of the discrepancy between experiment and prediction might possibly be explained by natural statistical variation.

In this analysis we attempted to account for the additional effect of the scatter of the elliptical-hole specimen dimensions on the predicted strength response using CARES/Life and ANSYS/PDS. It could be 
argued that the elliptical-hole data was contaminated by the variation of dimensions and should not have been used. This may be a valid point. But one of the goals of this paper was to show that other stochastic quantities or variables can effect the strength response and that modeling approaches can be formulated that can account for these variations. Being able to do this could have application to other problems where various uncertainties can creep into the manufacturing process.

\section{Conclusion}

The ability of the Weibull distribution to be used to predict the strength response of room-temperature $\mathrm{SiC}$ microtensile specimens with various stress concentrations was investigated using the NASA developed CARES/Life program. Analysis was performed assuming the strength controlling flaws resided on those material surfaces that were exposed to the etching process. The microtensile specimens had significant specimen-to-specimen variations in dimensions because of variations in the nickel mask used in the etching. We demonstrated with the single crystal SiC specimens that ANSYS-PDS and CARES/Life could be used together to account for this variation. This analysis was not rigorous mainly because isotropic material and fracture behavior was assumed. However, the simulation results showed good correlation for the circular-hole specimen geometry and some over prediction of the strength of the elliptical-hole specimens. These results tend to support using the Weibull distribution for design and analysis purposes of SiC MEMS - and probably for other MEMS brittle material systems as well-as long as the material can be modeled as a continuum, the flaw population of the tested specimen and the designed component remain the same, and size-effect extrapolation from the specimen baseline is kept prudently modest.

\section{References}

1. Epstein, "Millimeter-Scale, MEMS Gas Turbine Engines," Proceedings ASME Turbo Expo 2003 Power for Land, Sea, and Air; June 16-19, 2003, Atlanta, Georgia, USA. Paper No. GT-2003-38866.

2. G. Beheim, "Deep Reactive Ion Etching for Bulk Micromachining of Silicon Carbide," The MEMS Handbook, M. Gad-el-Hak, ed., CRC Press, (2002).

3. J. Bagdahn, W. Sharpe Jr., and O. Jadaan, "Fracture Strength of Polysilicon at Stress Concentrations," J. MEMS, 12, 3, 302-312 (2003).

4. O. Jadaan, N. Nemeth, J. Bagdahn, and W. Sharpe Jr., "Probabilistic Weibull Behavior and Mechanical Properties of MEMS Brittle Materials," J. Mat. Sci., 38, 20, 4087-4113, (2003).

5. N. Nemeth, L. Powers, L. Janosik, and J. Gyekenyesi, "CARES/Life Ceramics Analysis and Reliability Evaluation of Structures Life Prediction Program,” NASA/TM-2003-106316, (2003).

6. N. Nemeth, O. Jadaan, T. Palfi, and E. Baker, "Predicting the Reliability of Ceramics Under Transient Loads and Temperatures With CARES/Life," Probabilistic Aspects of Life Prediction, ASTM-STP 1450, W. Johnson \& B. Hillberry, Eds., ASTM International, (2004). Also; J. ASTM Int., vol. 1, no. 8, Paper ID JAI11578, (2004).

7. S. Reh, P. Lethbridge, D. Ostergaard, "Quality-Based Design with Probabilistic Methods," ANSYS Solutions, vol. 2, no. 2, (2000). http://www.ansys.com/assets/tech-papers/mems-solutions-4.pdf.

8. W. Sharpe Jr., O. Jadaan, G. Beheim, G. Quinn, and N. Nemeth, "Fracture Strength of Silicon Carbide Microspecimens," to be published, J. MEMS, (2005).

9. WWW.cree.com/ftp/pub/sicctlg_read_new.pdf, "Silicon Carbide Substrates," MAT-CATALOG.00D, Cree Materials, 4600 Silicon Drive, Durham, NC, 27703, (1998-2005).

10. W. Sharpe Jr., D. Danley, and D. LaVan, "Microspecimen Tensile Tests of A533-B Steel," Small Specimen Test Techniques, ASTM STP 1329, W. Corwin, S. Rosinski, and E. Van Walle, Eds., Am. Soc. for Testing and Materials, 497-512, (1998).

11. W. Sharpe Jr., D. LaVan, and R. Edwards, "Mechanical Properties of LIGA-Deposited Nickel for MEMS Transducers," Proceedings Transducers ‘97, Chicago, IL, 607-10, (1997). 
12. Ayon, R. Braff, C. Lin, H. Sawin, M. Schmidt, "Characterization of a Time Multiplexed Inductively Coupled Plasma Etcher," J. Electrochem. Soc., 146, 339-49 (1999).

13. W. Sharpe Jr., O. Jadaan, N. Nemeth, and G. Beheim, "Strength of Polycrystalline Silicon Carbide Microspecimens at Room and High Temperature," Proceedings of the 2004 SEM Annual Conference, Costa Mesa, CA, Session 84, Paper No. 405, (2004).

14. K. Chen, A. Ayon, and S. Spearing, "Controlling and Testing the Fracture Strength of Silicon on the Mesoscale," J. Am. Ceram. Soc., 83, 1476-80 (2000).

15. Chasiotis, W. Knauss, "The Mechanical Strength of Polysilicon Films: 1. The Influence of Fabrication Governed Surface Conditions," J. of the Mechanics and Physics of Solids 51, pp. 15331550, (2003).

16. Chasiotis, W. Knauss, "The Mechanical Strength of Polysilicon Films: 2. Size Effects Associated with Elliptical and Circular Perforations," J. of the Mechanics and Physics of Solids 51, pp. 15511572, (2003).

17. S. Reh, T. Palfi, and N. Nemeth, "Probabilistic Analysis techniques Applied to Lifetime Reliability Estimation of Ceramics," Paper No.APS-II-49 Glass. JANNAF 39th CS/27th APS/21st PSHS/3rd MSS Joint Subcommittee Meeting, Colorado Springs, Colorado, December 1-5, (2003). 
Public reporting burden for this collection of information is estimated to average 1 hour per response, including the time for reviewing instructions, searching existing data sources, gathering and maintaining the data needed, and completing and reviewing the collection of information. Send comments regarding this burden estimate or any other aspect of this collection of information, including suggestions for reducing this burden, to Washington Headquarters Services, Directorate for Information Operations and Reports, 1215 Jefferson Davis Highway, Suite 1204, Arlington, VA 22202-4302, and to the Office of Management and Budget, Paperwork Reduction Project (0704-0188), Washington, DC 20503.

\section{\begin{tabular}{l|l|l}
\hline 1. AGENCY USE ONLY (Leave blank) & 2. REPORT DATE & 3. REPORT TYPE AND DATES COVERED
\end{tabular}}

\section{TITLE AND SUBTITLE}

December 2005

Technical Memorandum

Fabrication and Probabilistic Fracture Strength Prediction of High-Aspect-Ratio

Single Crystal Silicon Carbide Microspecimens With Stress Concentration

6. AUTHOR(S)

Noel N. Nemeth, Laura J. Evans, Osama M. Jadaan, William N. Sharpe, Jr., Glenn M. Beheim, and Mark A. Trapp

\section{PERFORMING ORGANIZATION NAME(S) AND ADDRESS(ES)}

National Aeronautics and Space Administration

John H. Glenn Research Center at Lewis Field

Cleveland, Ohio 44135-3191

WBS-22-066-30-03

8. PERFORMING ORGANIZATION REPORT NUMBER

E-15309

\section{SPONSORING/MONITORING AGENCY NAME(S) AND ADDRESS(ES)}

National Aeronautics and Space Administration

Washington, DC 20546-0001

\section{SUPPLEMENTARY NOTES}

Prepared for the Journal of Thin Solid Films, Elsevier Science. Noel N. Nemeth, Laura J. Evans, and Glenn M. Beheim, NASA Glenn Research Center; Osama M. Jadaan, University of Wisconsin-Platteville, College of Engineering, 1 University Plaza, Platteville, Wisconsin 53818; William N. Sharpe, Jr., John Hopkins University, Department of Mechanical Engineering, 3400 N. Charles Street, Baltimore, Maryland 21218; and Mark A. Trapp, Carnegie Mellon University, Department of Mechanical Engineering, Pittsburgh, Pennsylvania 15213. Responsible person, Noel N. Nemeth, organization code RXL, 216-433-3215.

Unclassified - Unlimited

Subject Category: 39

Available electronically at http://gltrs.grc.nasa.gov

This publication is available from the NASA Center for AeroSpace Information, 301-621-0390.

\section{ABSTRACT (Maximum 200 words)}

Single crystal silicon carbide micro-sized tensile specimens were fabricated with deep reactive ion etching (DRIE) in order to investigate the effect of stress concentration on the room-temperature fracture strength. The fracture strength was defined as the level of stress at the highest stressed location in the structure at the instant of specimen rupture. Specimens with an elliptical hole, a circular hole, and without a hole (and hence with no stress concentration) were made. The average fracture strength of specimens with a higher stress concentration was larger than the average fracture strength of specimens with a lower stress concentration. Average strength of elliptical-hole, circular-hole, and without-hole specimens was $1.53,1.26$, and $0.66 \mathrm{GPa}$, respectively. Significant scatter in strength was observed with the Weibull modulus ranging between 2 and 6. No fractographic examination was performed but it was assumed that the strength controlling flaws originated from etching grooves along the specimen side-walls. The increase of observed fracture strength with increasing stress concentration was compared to predictions made with the Weibull stress-integral formulation by using the NASA CARES/Life code. In the analysis isotropic material and fracture behavior was assumed - hence it was not a completely rigorous analysis. However, even with these assumptions good correlation was achieved for the circular-hole specimen data when using the specimen data without stress concentration as a baseline. Strength was over predicted for the elliptical-hole specimen data. Significant specimen-to-specimen dimensional variation existed in the elliptical-hole specimens due to variations in the nickel mask used in the etching. To simulate the additional effect of the dimensional variability on the probabilistic strength response for the single crystal specimens the ANSYS Probabilistic Design System (PDS) was used with CARES/Life.

\section{SUBJECT TERMS}

Silicon carbide; Strength; Weibull, MEMS

\begin{tabular}{|c|c|}
\hline $\begin{array}{c}\text { 17. SECURITY CLASSIFICATION } \\
\text { OF REPORT } \\
\text { Unclassified }\end{array}$ & $\begin{array}{c}\text { 18. SECURITY CLASSIFICATION } \\
\text { OF THIS PAGE } \\
\text { Unclassified }\end{array}$ \\
\hline
\end{tabular}

\section{SECURITY CLASSIFICATION OF ABSTRACT \\ Unclassified}

15. NUMBER OF PAGES

18

16. PRICE CODE

\section{LIMITATION OF ABSTRACT}

Standard Form 298 (Rev. 2-89) 

